\section{MITI to shake up institutes}

\section{Tokyo}

THE first major reorganization of Japanese government laboratories in decades is now being planned by the Agency of Industrial Science and Technology (AIST), an arm of the powerful Ministry of International Trade and Industry (MITI). The plan to shuffle several research institutes in Tsukuba science city is intended to inject new life and greater flexibility into the government research system.

Tsukuba science city, which was created in the 1970 s by uprooting government research institutes from Tokyo and transplanting them to the rice paddy fields of Ibaraki Prefecturenerth af the zarpital vity; hes zeme-to life in the past few years with a sudden influx of private sector research institutes (see Nature 345, 378; 1990). But while some government research laboratories are flourishing in the new environment, others are bogged down in bureaucracy and an organizational structure that dates back to the beginning of this century. The latter category includes the four AIST institutes targeted for tronics researcher in Tsukuba calls "dinosaurs".

Those institutes are the National Chemical Laboratory for Industry, the Fermentation Research Institute, the Research Institute for Polymers and Textiles and the Industrial Products Research Institute. They have a total of more than 500 researchers and a combined annual budget of over $¥ 8,000$ million ( $\$ 60$ million).

If the AIST plan is put into effect, the four will be combined into two new institutes, one specializing in life sciences and the other in materials science.

In addition, AIST will establish an entirely new research centre for interdisciplinary research that will focus on nanotechnology and 'holistic science'.

Researchers in the life sciences and materials science are now scattered among various divisions of the four AIST institutes that are huddled together in one section of Tsukuba. The current plan is to bring all the life scientists into the present Fermentation reorganization, which one leading optoelec-
Research Institute and a new building to be constructed nearby, while putting the material scientists in the National Chemical Laboratory and the adjacent Research Institute of Polymers and Textiles, which will also get a new wing. The Industrial Products Research Institute, meanwhile, will be converted into the new interdisciplinary research centre, although a section of it will be set aside for the life scientists.

AIST officials expect the total outlay for new construction work to amount to $¥ 4,500$ million (\$33 million) over the next three years. The agency has already allocated

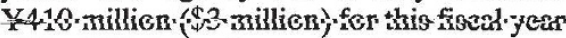
with which to begin construction of the new building.

The most radical element of the plan is the proposed new interdisciplinary research centre, which has several aspects that depart from normal Japanese practice.

Instead of having permanent staff employed on a lifetime basis - as is now the case in all government research laboratories - researchers will be assigned to the centre to work on projects for periods of three to five years. At the end of that time, the projects will undergo "severe" review, says Masayoshi Hamada of AIST, who is in charge of the reorganization.

Researchers will be drawn not only from AIST laboratories but also from private industry, universities and overseas. NonJapanese scientists will be involved in the planning stages of the projects, rather than just being invited as 'guests'. Hamada expects the centre to have a total complement of about 100 researchers.

In many respects, the new centre will resemble the Research Center for Advanced Science and Technology (RCAST) of Tokyo University and the Frontier Research Program (FRP) of the Institute of Physical and Chemical Research (RIKEN), based in the outskirts of Tokyo. RCAST and FRP are two successful anomalies recently created in the government research sector. RCAST has a number of chairs funded by private industry. RIKEN is a 'special corporation' (toku-

\section{Moving to nanotechnology}

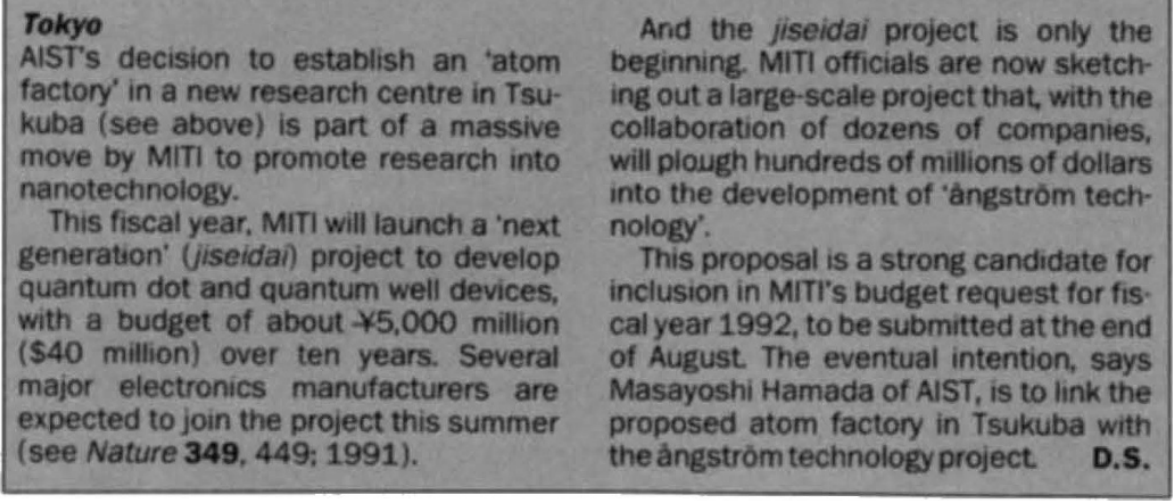

\section{Thier plans to leave Institute of Medicine}

Washington

SAmuel Thier, who presided over the US Institute of Medicine (IOM) for six years of unprecedented growth, is leaving to become president of Brandeis University. He said last week that he plans to leave IOM by 1 October, and that the institute is in the process of assembling a search committee to find a new president.

Part of the National Academy of Sciences, IOM is an independent body of scientists who provide the federal government, Congress and others with advice on biomedical issues. During Thier's tenure, the amount of IOM contract studies grew

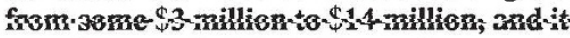
now has nearly 30 studies under way. In addition, an endowment was created and grew to the current level of $\$ 20$ million.

Asked why he is leaving for academic life at a time when IOM is doing well and the university community is facing cutbacks and stalled growth, Thier said that he is "intrigued by challenge". Brandeis, as the smallest and the youngest of the members of the research orientated Association of American Universities, "is an opportunity to do some interesting experiments in reorganization", he said.

Before joining IOM in 1985, Thier was chairman of the department of internal medicine at the Yale University School of Medicine.

ChristopherAnderson

shuhojin) and, although it is affiliated to the Science and Technology Agency, it has much greater freedom and flexibility to establish programmes such as FRP than do ordinary government research laboratories.

The AIST centre will concentrate on two seemingly contradictory themes. One group of researchers working in an 'atom factory' will examine and manipulate biological and inorganic material at the level of atoms and molecules with scanning tunnelling microscopes, atomic force microscopes and other devices for working at the nanometre level. A second group, working in the opposite direction from this reductionist approach, will study whole organisms, societies and technologies holistically.

AIST still faces one hurdle before its new plan can be implemented. The reorganization has to be approved by the Management and Coordination Agency, which, under a policy of fiscal restraint implemented in the early 1980 s, is steadily trimming the number of government employees, including researchers, to try to cope with the national government's chronic debt. AIST will submit a formal proposal to the agency in late August and a decision will be made at the end of the year. But AIST officials say they are confident of success because their plan does not require any increase in the number of permanent government employees.

David Swinbanks 